\title{
Vitamin C and E Supplementation Effects in Professional Soccer Players Under Regular Training
}

\author{
Claudio C. Zoppi ${ }^{1}$, Rodrigo Hohl ${ }^{2}$, Fernando C. Silva ${ }^{2}$, Fernanda L. Lazarim², Joaquim M. F. Antunes \\ $\mathrm{Neto}^{2}$, Mirtes Stancanneli ${ }^{2}$ And Denise V. Macedo ${ }^{2}$ \\ Laboratório de Pesquisa do Exercício, Faculdade Social da Bahia, Salvador, Brazil ${ }^{1}$. Laboratório de Bioquímica \\ do Exercício (LABEX), Universidade Estadual de Campinas, Campinas, Brazil ${ }^{2}$. Address correspondence to \\ czoppi@fsba.edu.br
}

Recieved August 31, 2006/Accepted November 27, 2006

\begin{abstract}
Exercise training is known to induce an increase in free radical production potentially leading to enhanced muscle injury. Vitamins $\mathrm{C}$ and $\mathrm{E}$ are well known antioxidants that may prevent muscle cell damage. The purpose of this study was to determine the effects of these supplemental antioxidant vitamins on markers of oxidative stress, muscle damage and performance of elite soccer players. Ten male young soccer players were divided into two groups. Supplementation group $(n=5)$ received vitamins $\mathrm{C}$ and $\mathrm{E}$ supplementation daily during the pre-competitive season ( $\mathrm{S}$ group), while the placebo group (PL group, $\mathrm{n}=5$ ) received a pill containing maltodextrin. Both groups performed the same training load during the three-month pre-season training period. Erythrocyte antioxidant enzymes glutathione reductase, catalase and plasma carbonyl derivatives did not show any significant variation among the experimental groups. Similarly, fitness level markers did not differ among the experimental groups. However, $\mathrm{S}$ group demonstrated lower lipid peroxidation and muscle damage levels $(\mathrm{p}<0.05)$ compared to PL group at the final phase of pre-competitive season. In conclusion, our data demonstrated that vitamin $\mathrm{C}$ and $\mathrm{E}$ supplementation in soccer players may reduce lipid peroxidation and muscle damage during high intensity efforts, but did not enhance performance. Journal of the International Society of Sports Nutrition. 3(2): 37-44, 2006
\end{abstract}

Keywords: lipid peroxidation, Carbonyl derivatives, anaerobic threshold, strenght, antioxidant systems

\section{INTRODUCTION}

It is well known that exercise training increases reactive oxygen species (ROS) formation, and the removal of these formed species depends on antioxidant systems ${ }^{1}$. If the rise of the level of ROS exceeds the antioxidant capacity to neutralize them, then cell lipids, proteins, and even DNA material may suffer oxidative damage ${ }^{2}$. Vitamins $\mathrm{C}$ and $\mathrm{E}$ are exogenous powerful antioxidant molecules that act together with other endogenous antioxidant systems within tissue cells in order to scavenge the formed ROS ${ }^{3}$. It has been suggested that athletes under heavy training and competition are not able to maintain optimal tissue levels of vitamins, even if the recommended daily allowances are consumed in their diets ${ }^{4}$. Furthermore, several studies have shown that antioxidant vitamin supplementation decreases oxidative damage in human subjects ${ }^{5-9}$.
Another interest that arises in antioxidant vitamin supplementation is the possible ergogenic effect in athletic performance. Some studies have provided evidence that in isolated muscle fibers, treatment with antioxidant vitamins reduced fatigue appearance induced by the rise in ROS formation ${ }^{10}$. The effects of dietary antioxidant vitamin supplementation on detoxifying exercise-induced increases in ROS production have been given special attention in recent years. However, most of these studies were carried out under laboratory conditions, and used voluntary subjects ${ }^{8,11-13}$, so little is known about the response of professional athletes under regular strenuous training. In one isolated study, Brites and colleagues ${ }^{14}$ have shown that soccer players participating in regular training demonstrated higher levels of oxidative stress damage, despite an increase in endogenous antioxidant capacity. Therefore, antioxidant vitamins supplementation might be a useful tool to avoid oxidative stress in this type of athlete. Based on 
these findings, the purpose of this study was to examine the effects of vitamins $\mathrm{C}$ and $\mathrm{E}$ supplementation on oxidative stress and performance parameters related to soccer players under regular training during their pre-competitive season. Our hypothesis is that vitamin $\mathrm{C}$ and $\mathrm{E}$ supplementation would decrease oxidative stress parameters, and perhaps enhance the athletic performance of soccer players.

\section{METHODS}

Subjects. Ten male young professional soccer players of the first Brazilian league, at mean age of $18 \pm 1$ years old, participated in the study. All subjects were from the same team that was in the pre-competitive phase of the training season, and were informed about all procedures and possible risks involved before they gave their written consent to participate. The study was also approved by the State University of Campinas Ethical comittee. The Players anthropometric characteristics were measured and are presented in Table 1. All subjects completed ten training sessions a week. Relative intensity and training volume were the same for all of them.

Table 1. Anthropometric characteristics of $S$ group $(n=5)$ and PL group $(n=5)$ subjects. Data are means \pm SD. LBM (Lean Body Mass).

\begin{tabular}{ccccc}
\hline & $\begin{array}{c}\text { AGE } \\
(\text { Years })\end{array}$ & $\begin{array}{c}\text { HEIGHT } \\
(\mathrm{cm})\end{array}$ & $\begin{array}{c}\text { WEIGHT } \\
(\mathrm{Kg})\end{array}$ & $\begin{array}{c}\text { LBM } \\
(\%)\end{array}$ \\
\hline S group & $18.3 \pm 0.5$ & $175.13 \pm 3.7$ & $71.2 \pm 2.4$ & $85 \pm 2.7$ \\
PL group & $18 \pm 1.0$ & $177.5 \pm 5.1$ & $70.16 \pm 4.1$ & $85.7 \pm 2.4$ \\
\hline
\end{tabular}

Training protocol. Pre-competitive season took ninety days and was divided in three different phases of training: Phase I (30 days): During this phase aerobic power was developed with high volumes and low intensity training loads. Phase II (30 days): In phase II strength capacity was trained with medium volume and high intensity training loads. Phase III (30 days): The final phase of this pre-season period was dedicated to improving speed and anaerobic power using low volume and very high levels of intense training.

Studydesign. The supplementation lasted the ninety days of pre-season training. It began on the first day of phase I and ended at the last day of the phase III, when pre-season also ended. Athletes were randomly divided into two groups, supplemented (S) and placebo (PL). The $\mathrm{S}$ group received in a double- blind manner $1000 \mathrm{mg}$ of ascorbic acid and $800 \mathrm{mg}$ of $\alpha$-tocopherol packed in capsules containing lyophilized powder (obtained from Roche ${ }^{\circledR}$ ) a day, divided in four doses of 250 and $200 \mathrm{mg}$ respectively over the whole period of ninety days. The PL group, whose preparation was identical in form, aspect and taste, but contained maltodextrin instead, received the same amount of capsules throughout the ninety days as well. To ensure an administration of double-blind type, capsules were stored in four identical bins, previously identified by using the names of the athletes who should have consumed them, within each specific bin. This procedure was performed by one of the researchers who did not have any contact with the athletes, and the distribution of the capsules among playeres was performed by a nutritionist who similarly was not acquainted with the content of the capsules. Since subjects had all their meals at the team's restaurant, diet was carefully controlled to ensure adequate macro and micro nutrients (Table 2). The athlete's diet in both groups was designed to adhere to the Recommended Dietary Allowances (RDA) specifications relative to macronutrients and micronutrients, including vitamin $\mathrm{C}$ and $\mathrm{E}$. This was done to ensure that $\mathrm{S}$ group subjects had ingested higher levels of these vitamins, above those of RDA. $\mathrm{S}$ and PL athletes diet composition was developed using individual total energy expenditure, taking into account metabolic basal costs and adding to exercise training costs, with the help of a specific nutritional software. Diet was planned to provide the same amount of expended energy. Athletes were strongly advised not to have meals out of the club, but if it was the case, they had to report what was eaten to the nutritionist and diet was readjusted. The athletes were also asked not to consume any other nutritional supplement during test period. Although it was not rigorously measured, compliance with treatment was high since few athletes reported adjustment of their schedule of meals.

Blood sampling. Blood samples were collected in the morning in heparinized tubes, 48 hours after the last training session of the week, at three different points of the season: PRE) before supplementation start, MID) in the middle of the season and AFTER) after the end of the pre-competitive season. Blood was centrifugated for 15 minutes at $3000 \mathrm{rpm}$, plasma was stored at $-70^{\circ} \mathrm{C}$ until assays were conducted. It was then tances (TBARs) levels, creatine kinase (CK) activity and carbonyl derivatives (CD). Afterwards, red blood cells were centrifugated for 5 minutes at $3000 \mathrm{rpm}$ in a saline phosphate buffer (PBS) $5 \mathrm{mM}$ medium, containing $\mathrm{NaCl} 0.9 \%$. It was washed three times and then 
diluted in water $(1: 1 \mathrm{v} / \mathrm{v})$ and also stored at $-70^{\circ} \mathrm{C}$ until antioxidant enzymes assays were conducted ${ }^{15}$.

Table 2. Daily energy, macronutrient, vitamin $\mathrm{C}$, vitamin $\mathrm{E}$ intake and contribution (\%) of macronutrients to energy intake of subjects. Data are means \pm SD.

\begin{tabular}{|c|c|c|}
\hline NUTRIENT & $\begin{array}{c}S \text { group }(n=5) \\
\text { mean } \pm \text { SD }\end{array}$ & $\begin{array}{c}\text { PL group }(n=5) \\
\text { mean } \pm \text { SD }\end{array}$ \\
\hline $\begin{array}{l}\text { Total Energy Intake } \\
\text { (Kcal) }\end{array}$ & $3435 \pm 358$ & $3567 \pm 422$ \\
\hline $\begin{array}{l}\text { Carbohydrate } \\
\left(\mathrm{Kcal}_{\mathrm{K}} \mathrm{Kg}^{-1}\right)\end{array}$ & $50.2 \pm 10.2$ & $53.6 \pm 8.2$ \\
\hline Protein $\left(\mathrm{Kcal} . \mathrm{Kg}^{-1}\right)$ & $1.7 \pm 0.4$ & $1.9 \pm 0.6$ \\
\hline$\alpha$-tocopherol (mg) & $3.4 \pm 0.6$ & $3 \pm 0.8$ \\
\hline Ascorbic acid (mg) & $28 \pm 2.1$ & $27 \pm 3.5$ \\
\hline $\begin{array}{l}\text { Carbohydrates } \\
\text { (\% of calories) }\end{array}$ & $59 \pm 10$ & $55 \pm 15$ \\
\hline $\begin{array}{c}\text { Protein } \\
\text { (\% of calories) }\end{array}$ & $13.2 \pm 4.1$ & $12.8 \pm 3.6$ \\
\hline $\begin{array}{c}\text { Fat } \\
(\% \text { of calories) }\end{array}$ & $27.7 \pm 5.2$ & $29.4 \pm 8.3$ \\
\hline
\end{tabular}

Table 3: Performance parameters after 3 months of vitamin $\mathrm{C}$ and $\mathrm{E}$ supplementation. Data are means $\pm \mathrm{SD}$.

\begin{tabular}{|c|c|c|c|c|}
\hline $\begin{array}{l}\text { Performance } \\
\text { Parameters }\end{array}$ & $\begin{array}{c}\text { S } \\
\text { GROUP } \\
\boldsymbol{P R E} \\
\end{array}$ & $\begin{array}{c}\text { S } \\
\text { GROUP } \\
\boldsymbol{P O S T}\end{array}$ & $\begin{array}{c}\text { PL } \\
\text { GROUP } \\
\boldsymbol{P R} \boldsymbol{E} \\
\end{array}$ & $\begin{array}{c}\text { PL } \\
\text { GROUP } \\
\text { POST }\end{array}$ \\
\hline $\operatorname{AT}\left(\mathrm{Km} \cdot \mathrm{h}^{-1}\right)$ & $10.2 \pm 2.3$ & $13.6 \pm 1.1^{* \#}$ & $10.8 \pm 1.5$ & $14 \pm 1.5^{* \#}$ \\
\hline Speed $\left(\mathrm{m} . \mathrm{s}^{-1}\right)$ & $7.1 \pm 1.0$ & $7.8 \pm 0.8$ & $7.4 \pm 0.3$ & $7.5 \pm 0.5$ \\
\hline $\begin{array}{l}\text { Strength } \\
\text { (Kg) }\end{array}$ & $15.0 \pm 3.3$ & $23 \pm 5.2^{* \#}$ & $16.2 \pm 2.2$ & $25 \pm 3.5^{* \#}$ \\
\hline
\end{tabular}

$* \mathrm{P}<0.05$ compared to the same group PRE values, \# $\mathrm{p}<0.05$ compared to other group PRE values.

Analytical methods. Antioxidant enzymes, glutathione reductase (GR) (E.C.1.8.1.7) and catalase (CAT) (E.C. 1.11.1.6) were measured with the help of a DU-640 Beckmann UV-VIS spectrophotometer according to the methods of Smith et al. ${ }^{16}$ and Aebi ${ }^{17}$, respectively. Carbonyl derivatives were measured spectrophotometrically using 2,4 dinitrophenylhydrazine according to Faure \& Lafond 18. Thiobarbituric acid reactive substances (TBARs) were measured using a SLM-Aminco Fluorometer according to Yagi ${ }^{19}$. Plasma CK was measured using the specific MPR3 CK NAC-activated Kit (Boehringer Mannhein) .

Performance parameters. Performance parameters were measured before the beginning of the season and after the end of it. These parameters included aerobic capacity, strength, and speed. Aerobic capacity was measured by the anaerobic threshold. It was measured in a track field according to the lactate minimum speed (LMS) protocol. Athletes were submitted to a high intensity bout of exercise to induce blood lactate concentration increase, and after pre-test they started a progressive exercise protocol until lactate U-Shaped curve stated by this protocol was reached, assuming the turning point as the anaerobic threshold speed ${ }^{20}$. Two-legged knee extension one maximal repetition (1RM) was used as parameter of strength. This test was conducted according to the American College of Sports Medicine guidelines for exercise and testing prescription ${ }^{21}$. First subjects warmed up perfoming 3 sets with low load that allowed 20 repetitions with 30 s of rest between each one. The initial load of 1RM test was stablished based on individual training loads. Rest between 1RM trials was set as $5 \mathrm{~min}$. Maximal speed was measured in a 30-meter maximal sprint. Athletes were asked to perform three sprints using their own soccer shoes on a specific grass field lane and the best result was considered. Maximal speed values were obtained with five photocells that were placed in paralell with the sprint lane, disposed $6 \mathrm{~m}$ one from the other. They were then used to measure, with accurate precision, the time of each subject. Photocells data was sent to a specific software that calculated athletes' speed test parameters, including maximal speed.

Statistical Analysis. The changes between intergroupal analysis PRE and POST, on S and PL groups, were tested by using the student t-test, and for the intragroupal analysis the "One-Way ANOVA" was used with the Tukey test as post hoc. The level of significance was set for all analysis at $\mathrm{P}<0.05$. GraphPad Instat software (San Diego, CA) was used to conduct statistical analysis and results were expressed as means and standard deviation of the mean. Due to the small sample size $(n=5)$, our statistical power was low (2.0 for student $t$ test and 2.3 for one-way ANOVA), and thus we needed a larger effect size (ES), correponding to a Pearson correlation coefficient of $\mathrm{r}=0.371$ corresponding to a 0.8 Cohen's $d$ index of ES value ${ }^{22}$. We also calculated the variation coefficient $(\mathrm{CV})$ for all performed tests to enhance our power to analyze the supplementation effects on all measured parameters. 
Statistical power and effect size calculations were conducted using the Piface specific software ${ }^{23}$.

\section{RESULTS}

Despite the reduced amount of data we acquired due to the small sample size, the group of athletes who participated in this study was very homogeneous. This can be confirmed by the small degree of variation in most of the studied parameters, showed by the SD and CV, thus enhancing ES $r$ values and our analysis power. As shown in tables I and II the anthropometric characteristics, energy, dietary macronutrients and vitamins $\mathrm{C}$ and $\mathrm{E}$ intake were close, but not the same in S and PL groups. All of these measurements showed $\mathrm{p}$ values above 0.05 , ranging from 0.2 to 0.84 , ES $r$ above 0.371 , ranging from 0.45 to 0.57 comparing S and PL groups and mean $\mathrm{CV}$ values of $12.9 \%$ to $\mathrm{S}$ group ( range: $2.1-$ 31 ) and $16 \%$ to PL group (range: $0.02-31$ ).

As indicated on Table 3 our supplementation protocol did not induce any statistical difference in aerobic capacity, strength and speed between $\mathrm{S}$ and PL groups, at the end of the season, but it has showed a significant increase $(p<0.05)$ for AT and strength, high ES $r$ values of $0.68,0.37$ and 0.67 in S group and $0.72,0.32$ and 0.83 in PL group for AT, speed and strength respectively, induced by the training protocol between PRE and POST measurements with $\mathrm{CV}$ values ranging from 8 to $22 \%$ in $\mathrm{S}$ and 4 to $14 \%$ in PL group.

Blood antioxidant enzymes, oxidative and damage markers measured at baseline (PRE), MID and POST pre-competitive season period are shown in figures 1 , 2 and 3. S and PL did not show any intra-group variation for CAT, GR, CD, TBARs and $\mathrm{CK}$. PL and $\mathrm{S}$ groups data MID and POST compared to baseline PRE were not significantly different with $\mathrm{p}$ values being of 0.11 and 0.64 for CAT, 0.48 and 0.87 for GR, 0.9 and 0.055 for $\mathrm{CD}, 0.13$ and 0.68 for TBARs and 0.34 and 0.052 for $\mathrm{CK}$, for PL and $\mathrm{S}$ groups respectively with CVs ranging between 12 and $32 \%$ in all measurements.

Our results showed that antioxidant enzymes activity and carbonyl derivative levels were not different between S and PL groups throughout the season as well. On the other hand CK and TBARs levels, showed on figures $2 \mathrm{~B}$ and 3 , demonstrated significantly increased levels $(p<0.05)$ at the same time-point, plasma $\mathrm{CK}$ activity in PL group was about $50 \%$ higher than the $\mathrm{S}$ group. Additionally, plasma TBARs concentration was about $66 \%$ higher in the PL group than the S group after the final phase of training. ES $r$ values for PL and S comparisons in most of cases remained high, above 0.37 , only in five measurements CAT POST, GR MID, GR POST, CD and CK MID, ES $r$ values were respectively 0.25 , $0.3,0.28,0.33$ and 0.35 with a mean $\mathrm{CV}$ of $13 \%$ for $\mathrm{S}$ and PL comparisons.

A

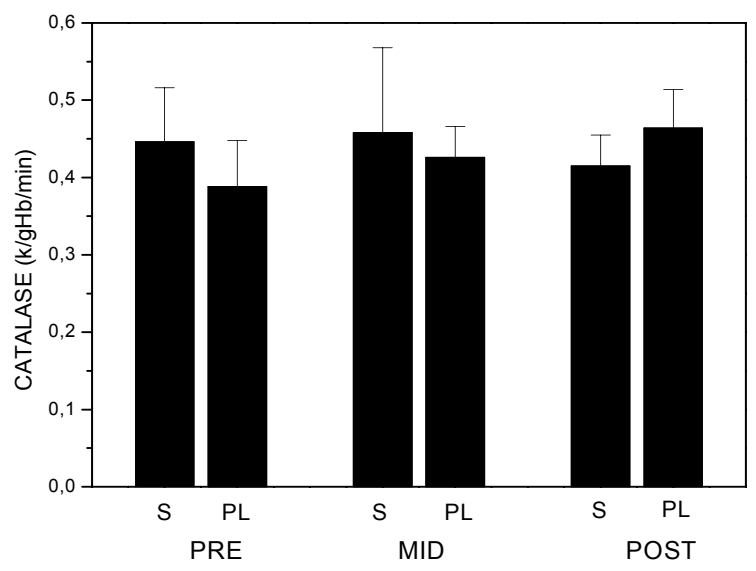

B

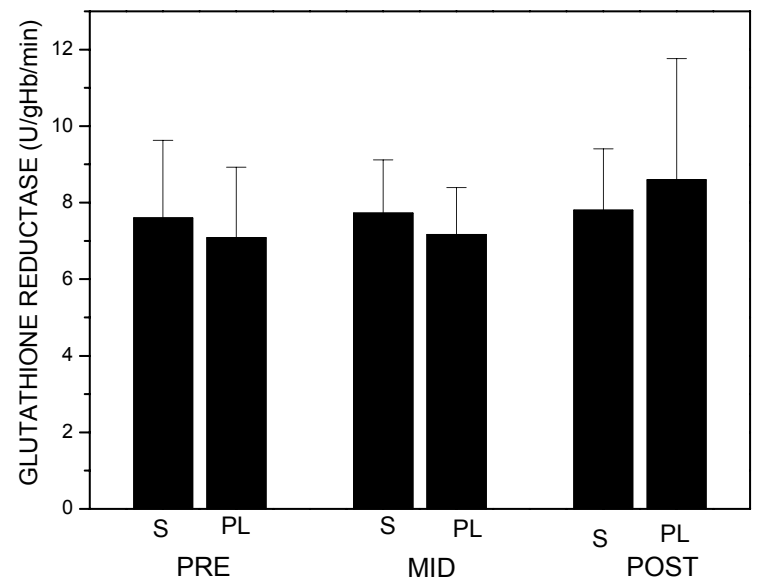

Figure 1: Blood catalase activity (A) and glutathione reductase activity (B) at the beginning (PRE), in the middle (MID) and after pre-competitive season (POST) of $\mathrm{S}$ group $(\mathrm{n}=5)$ and $\mathrm{PL}$ group $(\mathrm{n}=5)$ subjects. Data are means $\pm \mathrm{SD}$.

\section{DISCUSSION}

Although many studies have focused antioxidant vitamins supplementation and exercise, few demonstrated their effects in elite professional athletes and even less is known about it in soccer players ${ }^{3,28}$. So in this paper, our purpose was to determine the effects of vitamin $\mathrm{C}$ and $\mathrm{E}$ supplementation in elite soccer players during regular training. Several studies have shown that antioxidant enzyme activity increases with oxidative stress and exercise training in skeletal muscle and 
A

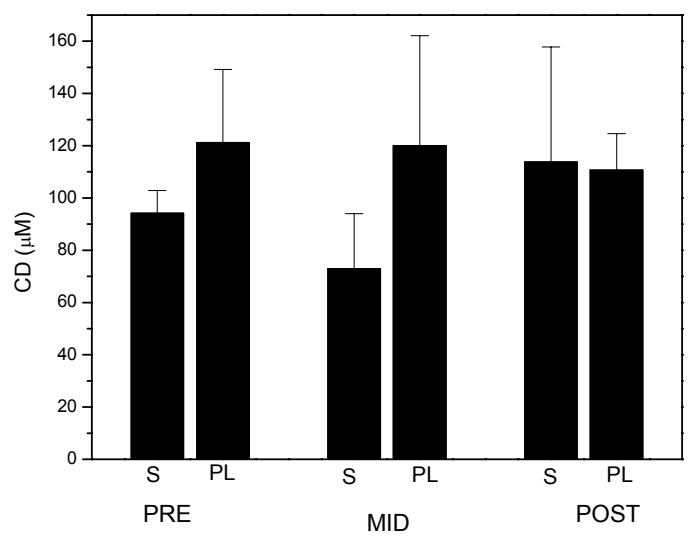

B

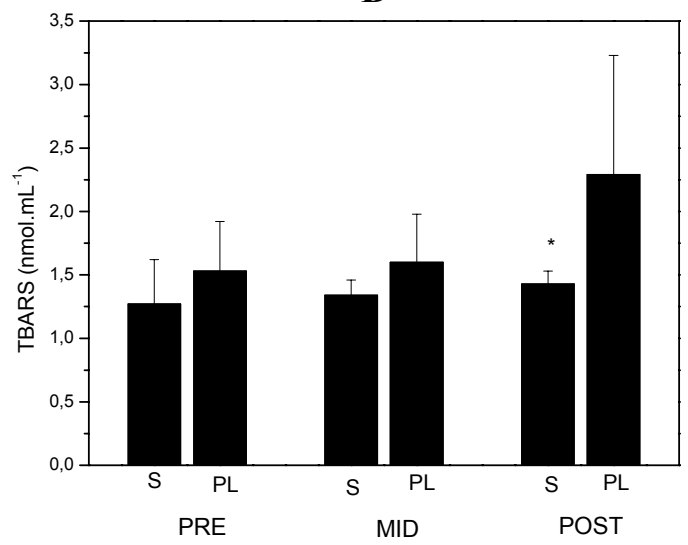

Figure 2: Blood CD (A) and TBARs (B) at the beginning (PRE), in the middle (MID) and after pre-competitive season (POST) of $S$ group $(n=5)$ and PL group $(n=5)$ subjects. Data are means \pm SD. $* \mathrm{p}<0.05$ compared with PL group at the same moment of season.

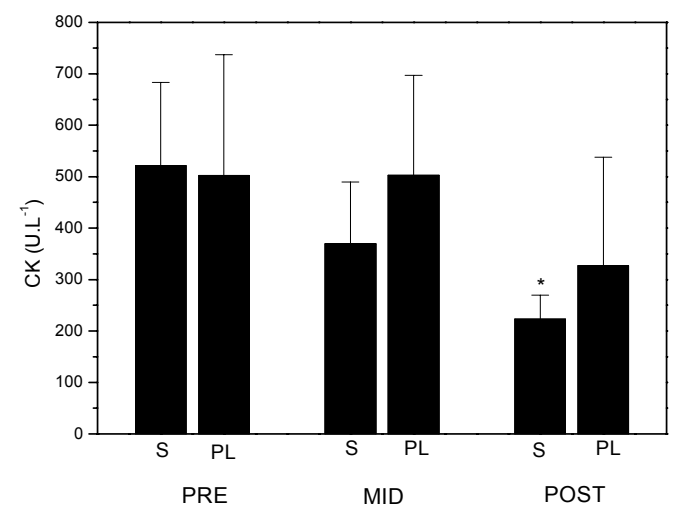

Figure 3: Plasma CK activity at the beginning (PRE), in the middle (MID) and after pre-competitive season (POST) of $\mathrm{S}$ group $(n=5)$ and PL group $(n=5)$ subjects. Data are means \pm SD. $* p<0.05$ compared with PL group at the same moment of season. blood ${ }^{26-27}$. However, the increase in antioxidant defenses might not follow the same increasing proportion in pro-oxidants events and thus affect the requirements for dietary antioxidants such as vitamin $\mathrm{C}$ and E. Despite a high controlled study, the main limitation of this paper is the low statistical power due to the limited number of subjects who constituted our sample, so we have to take into account when considering our results that the lack of significance in some of the measured variables may have been due to the small sample size.

Antioxidant enzymes. Fang and colleagues ${ }^{29}$ proposed that antioxidant enzymes activity upregulation occurred following antioxidant vitamins supplementation, mainly by the use of vitamin E. Our data are not in agreement with this statement, since blood antioxidant enzymes glutathione reductase and catalase in soccer players did not show differences between PL and S, at any time during our supplementation protocol. This response was expected since antioxidant vitamins $\mathrm{C}$ and $\mathrm{E}$ didn't act directly with these enzymes, and neither did part of the molecule structure of both studied enzymes GR and CAT nor even their co-factors, like nicotinamide, riboflavine and thiamine vitamins do. On the other hand, there are some evidences that vitamin E deficiency may reduce antioxidant enzymes catalase and glutathione reductase activities possibly induced by enhanced oxidative stress ${ }^{30-31}$. Based on these findings and on our results we can conclude that RDA antioxidant vitamins amounts are sufficiently enough to guarantee the maintenance of antioxidant enzymes activity level in elite soccer players, as we did not detect decreases in PL blood antioxidant enzymes activity.

Oxidative stress and muscle damage markers. Various indicators have been used to characterize of oxidative stress on muscle fibers and tissue injury. Here, we have used plasma CD and TBARs as well as the degree of CK leakage into blood as oxidative stress and muscle damage markers. CD has been used as a good indicator of oxidative stress ${ }^{32}$ and TBARs, despite lots of criticism its measurement, it is the most widely lipid peroxidation marker used in literature ${ }^{33}$. CD levels were not different throughout the season between our experimental groups, indicating that both groups had the same level of oxidatively modified proteins. This result is in agreement with other studies that showed no increase in protein oxidation induced by exercise at sea level 34-36 and although antioxidant vitamins supplementation seems to reduce it ${ }^{37}$, our data did not show differences between S and PL groups. A 
possible explanation to this finding is the increase in plasma total antioxidant capacity detected in soccer players after specific training ${ }^{14,38}$. Plasma antioxidant capacity enhancement could be itself the reason why CD didn't show any variation in our subjects or there can still be another repairing process acting in order to maintain proteins structures intact, like the HSP chaperones mechanism, as it has been reported to be increased in plasma after exercise ${ }^{39}$.

Myofibrillar proteins such as, lactate dehydrogenase, myoglobin and creatine kinase in plasma or serum are often used as indicators of muscle damage ${ }^{27,39,40}$. Although controversy exists, lipid peroxidation appears to be an important mechanism underlying exercise-induced muscle damage and a large number of studies correlate CK plasma release and lipid peroxidation. Maughan et al. ${ }^{41}$ found increased plasma TBARs and CK levels after a $45 \mathrm{~min}$ bout of downhill running. Kanter et al. ${ }^{42}$ found a close relationship between plasma MDA and CK in long distance runners and more recently Hinchcliff et al. ${ }^{43}$, using a more specific biomarker for lipid peroxidation also found a positive correlation between $\mathrm{F}_{2 \alpha}$-isoprostanes with plasma $\mathrm{CK}$ and a negative correlation with serum vitamin $E$. The relationship between muscle enzymes release and biomarkers of oxidative stress, mainly lipid peroxidation, showed by the above mentioned studies is thought to be achieved by increased sarcollemal permeability ${ }^{28}$. However not all studies have shown this same relationship ${ }^{44-46}$, this difference might be related to exercise protocol (i.e. intensity/ volume) or even in dietary supplement protocol.

Our results have shown lower levels of lipid peroxidation and muscle damage in elite soccer players evidenced by TBARs and CK $(p<0.05)$ plasma levels in $\mathrm{S}$ group. The lack of difference in antioxidant enzymes activity reported in our data, also suggests that antioxidant vitamins supplementation may be the responsible for this difference observed in $\mathrm{S}$ group lipid peroxidation. Data are in agreement with other studies that reported lower lipid peroxidation and CK levels in supplemented athletes after several kinds of effort $9,11,47,48$. Therefore, the finding of $S$ group TBARs and CK levels being lower only after the end of the final phase of the season, may reflect a higher intensity of effort at this phase. Another possible explanation for this finding remains in the absence of a wash-in period in this study, since vitamin $\mathrm{E}$ concentration takes nearly 30 to 48 days to increase in tissues. This data can also be interpreted as the result of vitamin $\mathrm{E}$ peak concentration in muscle at the end of pre-season period.

Performance parameters. Optimal physical performance capacity is unlikely to be achieved without optimum cellular function. Strenuous exercise imposes situations that lead subject cell metabolism and structure to significant stress, including those of oxidative stress and muscle damage $8,41,42$. Oxidative stress can still alter cell redox status that has an optimum range for muscle fibers functions ${ }^{49}$ and consequently alter performance. Some studies have provided evidence of oxidative stress on muscle fatigue-induced decreased performance in isolated muscle fibers ${ }^{10,50}$, and treatment with antioxidants has shown to reduce the onset of fatigue ${ }^{51}$. On the other hand, no single study has detected whole body ergogenic effect of antioxidant vitamins supplementation on performance or fatigue onset process. Lawrence et al. ${ }^{47}$, and Rokitzki et al. ${ }^{48}$, did not find changes in lactate threshold in vitamin E supplemented cyclists and swimmers respectively. Similarly Shephard et al. 52 didn't detect alterations on muscle strength nor maximal oxygen uptake ${ }^{53}$.

Our results are in agreement with these findings, since we have not detected differences in anaerobic threshold, muscle strength and speed in soccer players after a three-month vitamin $\mathrm{C}$ and $\mathrm{E}$ supplementation between the experimental PL and $\mathrm{S}$ groups. We have demonstrated, as expected, a significant $(\mathrm{p}<0.05)$ increase in AT and strength as result of exercise training protocol between PRE and POST measurements. Our data agreed with the work of Thompson et al. ${ }^{54}$ and indicates that vitamin $\mathrm{C}$ and $\mathrm{E}$ supplementation can bring modest benefit for elite soccer players even under strenuous training, since it attenuated lipid peroxidation and muscle CK leakage, but did not have a direct ergogenic effect on physical performance. The reasons why antioxidant vitamin supplementation could prevent fatigue in isolated muscle fibers, although it cannot act as an ergogenic aid in the whole body of athletes are not yet understood, and further studies are needed to clarify this issue.

\section{ACKNOWLEDGEMENTS}

Authors thank Fundação de Amparo a Pesquisa do Estado de São Paulo (FAPESP) and CNPq (Proc. 00/07962-2 and 523383-96-7) for the financial support and to the athletes who took part of this study. 


\section{REFERENCES}

1. Powers SK, Ji LL, Leeuwenburgh C. Exercise training-induced alterations in skeletal muscle antioxidant capacity: a brief review Med. Sci. Sports Exerc. 1999; 31(7): 987-997.

2. $\quad$ Packer L. Oxidants, antioxidants, nutrients and the athlete. J. Sports Sci. 1997; 15: 353-363.

3. Evans WJ. Vitamin E, vitamin C and exercise. Am. J. Clin. Nutr., 2000; 72 (suppl): 647S-521S.

4. Colgan M. The effects of micronutrient supplementation on athletic performance. In: Katch, F.I. (Ed.) Sport,Health, and nutrition 1986. Human Kinetics: pp 21-50.

5. Jakeman P, Maxwell S. Effects of antioxidant vitamin supplementation on muscle function after eccentric exercise. Eur. J. Appl Physiol. 1993; 67: 426-430.

6. Kanter MM, Nolte LA, Holloszy JO. Effects of an antioxidant vitamin mixture on lipid peroxidation at rest and postexercise. $J$. Appl. Physiol. 1993; 74: 965-969.

7. Maxwell SR, Jakeman P, Thomason H, et al. Changes in plasma antioxidant status during eccentric exercise and the effect of vitamin supplementation. Free Radic. Res. Commun. 1993; 19: 191-201.

8. Alessio HM, Goldfarb AH and Cao G. Exercise-induced oxidative stress before and after vitamin C supplementation. Int. J. Sports Nutr. 1997; 7: 1-9.

9. Schröder H, Navarro E, Tramullas A. et al. Nutrition antioxidant status and oxidative stress in professional basketball players: Effects of a three compound antioxidative supplement. Int. J. Sports Med. 2000; 21: 146-150.

10. Brotto MA, Nosek TM. Hydrogen peroxide disrupts $\mathrm{Ca} 2+$ release from the sarcoplasmic reticulum of rat skeletal muscle fibers. $J$. Appl. Physiol. 1996; 81(2):731-737.

11. Sumida S, Tanaka K, Kitao H, Nakadomo F. Exercise-induced lipid peroxidation and leakage enzyme before and after vitamin E supplementation. Int. J. Biochem. 1989; 21: 835-838.

12. Clarkson PM. Vitamins and trace minerals. In: Lamb, D.R., Willians, M.H., eds. Ergogenics-enhancement of performance in exercise and sport. 1991 Carmel, Cooper Publishing Group, 23-176.

13. Meydani M, Evans WJ, Handelman G. et al. Protective effect of vitamin E on exercise-induced oxidative damage in young and older adult. Am. J. Physiol. 1993; 264: R992-R998.

14. Brites FD, Evelson PA, Christiansen MG. et al. Soccer players under regular training showed imcreased oxidative stress but an improved plasma antioxidant status. Clin. Sci. (Lond) 1999; 96(4): 381-385.

15. Andersen HR, Nielsen JB, Nielsen F. et al. Antioxidative enzyme activities in human erythrocytes. Clin. Chem. 1997; 43(4): 562568 .

16. Smith IK, Vierheller TL, and Thorne CA. Assay of glutathione reductase in crude tissue homogenates using 5,5'-dithio-bis(2nitrobenzoic acid). Assay of glutathione reductase in crude tissue homogenates using 5,5'-dithio-bis(2-nitrobenzoic acid). Anal. Biochem. 1988; 175: 408-413.

17. Aebi H. Catalase in vitro. Methods Enzymol. 1984; 105: 121-126.

18. Faure P. and Lafond JL. Measurement of plasma sulphydryl and carbonyl groups as a possible indicator of protein oxidation. (1995) In: Analysis of free radicals in biological systems. Favier et alii. Eds. Verlag, Boston, 237-248.

19. Yagi K. Lipid peroxides and human diseases. Chem. Phys. Lipids 1987; 45: 337-351.

20. Tegtbur U, Busse MW, Braumann KM. Estimation of an individual equilibrium between lactate production and catabolism during exercise. Med. Sci. Sports Exerc. 1993; 25(5):620-627.

21. ACSM's guidelines for exercise and testing prescription.(2005) Baltimore, MD: Lippincott, Williams \& Wilkins.

22. Cohen J. Statistical power analysis for the behavioral sciences. (1988) Hillsdale, NJ: Lawrence Earlbaum Associates.

24. Lenth RV. Java Applets for Power and Sample Size [Computer software]. 2006. Retrieved November, 10, 2006 from http://www.stat.uiowa.edu/ rlenth/Power.

25. Meydani M, Fielding RA, Cannon JG. et al. Muscle uptake of vitamin E and its association with muscle fiber type. J. Nutr. Biochem. 1997; 8: 74-78.

26. Duthie GG, Robertson JD, Maughan RJ. Et al. Blood antioxidant status and erytrocyte lipid peroxidation following distance running. Arch. Biochem. Biophys. 1990; 282(1): 78-83.

27. Marzatico F, Pansarasa O, Bertorelli L. et al. Blood free radical antioxidant enzymes and lipid peroxides following long-distance and lactacidemic performances in highly trained aerobic and sprint athletes. J. Sports Med. Phys. Fitness. 1997; 37(4):235-239.

28. Sacheck JM and Blumberg JB. Role of vitamin E and oxidative stress in exercise. Nutrition. 2001; 17: 809-814.

29. Fang YZ, Yang S and Wu G. Free radicals, antioxidants and nutrition. Nutrition. 2002; 18: 872-879.

30. Carr AC, Zhu BZ, Frei B. Potential anteatherogenic mechanisms of ascorbate (vitamin C) and $\alpha$-tocopherol (vitamin E). Circ. Res. 2000; 87: 349.

31. Muller DP. Antioxidant therapy in neurological disorders. Adv. Exp. Med. Biol. 1990; 264: 475-484.

32. Chevion M, Berenshtein E and Stadtman, ER Human studies related to protein oxidation: protein carbonyl content as a marker of damage. Free Radical Biol. Med. 2000; 33: S99-S108.

33. Jenkins RR. Exercise and oxidative stress methodology: a critique. Am. J. Clin. Nutr. 2000; 72(2 Suppl):670S-674S. Review.

34. Gohil K, Packer L, De Lumen B, et al. Vitamin E deficiency and vitamin C supplements: exercise and mitochondrial oxidation. $J$. Appl. Phisiol, 1986; 60: 1986-1991.

35. Radak Z, Asano K, Lee KC. et al. High altitude training increases reactive carbonyl derivatives but not lipid peroxidation in skeletal muscle of rats. Free Radic. Biol. Med. 1997; 22(6):1109-1114.

36. Radak Z, Sasvari M, Nyakas C. et al. Exercise preconditioning against hydrogen peroxide-induced oxidative damage in proteins of rat myocardium. Arch. Biochem. Biophys. 2000; 376(2):248-251.

37. Reznick A, Witt EH, Matsumoto M and Packer L. Vitamin E inhibits protein oxidation in skeletal muscle of resting and exercised rat. Biochem. Biophys. Res. Commun. 1992; 189(2):801-806.

38. Cazzola R, Russo-Volpe S, Cervato G, Cestaro B. Biochemical assessments of oxidative stress, erythrocyte membrane fluidity and antioxidant status in professional soccer players and sedentary controls. Eur. J. Clin. Invest. 2003; 33(10): 920-924. 
39. Walsh RC, Koukoulas I, Garnham A. et al. Exercise increases serum Hsp72 in humans. Cell Stress Chaperones. 2001; 6(4):386393.

40. Clarkson PM and Tremblay I. Exercise-induced muscle damage, repair and adaptations in humans. J. Appl. Physiol. 1988; 65: 1-6.

41. Maughan RJ, Donnelly A, Gleeson M, et al. Delayed-onset muscle damage and lipid peroxidation in man after a downhill run. Muscle Nerve. 1989; 12: 332-336.

42. Kanter M, Lesmes G, Kaminsky L. et al. Serum creatine kinase and lactate dehydrogenase changes following an eighty kilometer race. Eur. J. Appl. Physiol. 1988; 57: 60-63.

43. Hinchcliff KW, Reinhart GA, DiSilvestro R. et al. Oxidant stress in sled dogs subjected to repetitive endurance exercise. Am. $J$. Vet. Res. 2000; 61(5):512-517.

44. Saxton J, Donnelly A, Roper H. Indices of free radical mediated damage following maximum voluntary eccentric and concentric muscular work. Eur. J. Appl. Physiol. 1994; 68: 189-193.

45. Viinikka L, Vuori J, Ylikorkala O. Lipid peroxides, prostacyclin, and thromboxane $\mathrm{A}_{2}$ in runners during accute exercise. Med. Sci. Sports Exerc. 1984; 16: 275-277.

46. Wang J, Lin C, Chen J, Wong, M. Role of chronic exercise in decreasing oxidized LDL-potentiated platelet activation by embancing platelet derived NO release and bioactivity in rats. Life Sci. 2000; 66: 1937-1948.

47. Lawrence J, Bower R, Riehl W, Smith, J. Effects of Alpha-tocopherol acetate on the swimming endurance of trained swimers. Am. J. Clin. Nutr. 1979; 28: 205-208.

48. Rokitzki L, Logemann E, Huber G. et al. Alpha-tocopherol supplementation in raccing cyclists during extreme endurance training. Int. J. Sport Nutr. 1994; Sep 4: 253-264.

49. Reid MB. Redox modulation of skeletal muscle contraction: What we know and what we don't. J. Appl. Physiol. 2001; 90: 724731.

50. Essig DA, Nosek TM. Muscle fatigue and induction of stress protein genes: a dual function of reactive oxygen species? Can. $J$. Appl. Physiol. 1997; 22(5):409-28.

51. Reid MB, Stokic DS, Koch SM. et al. N-acetylcysteine inhibits muscle fatigue in humans. J. Clin. Invest. 1994; 94(6):2468-2474.

52. Shephard RJ, Campbell R, Pimm P. et al. Vitamin E, exercise, and the recovery from physical activity. Eur. J. Appl. Physiol. 1974; 33: 119-126.

53. Sharman IM, Down MG, Sen RN. The effects of vitamin E and training on physiological function and athletic performance in adolescent swimmers. Br. J. Nutr. 1971; 26: 265-276.

54. Thompson D, Williams C, McGregor SJ, Nicholas CW, McArdle F, Jackson MJ, Powell JR. Prolonged vitamin C supplementation and recovery from demanding exercise. Int J Sport Nutr Exerc Metab. 2001 Dec;11(4):466-81. 